\title{
Avaliação de cenários acerca do transporte de pessoas em uma instituição de ensino superior: terceirização versus utilização de veículos próprios
}

A modernização e expansão do ensino superior no Brasil exigiu o uso de melhores práticas, aumento de eficiência e eficácia por parte das Instituições Federais de Ensino Superior (IFES). Neste sentido, a mensuração dos custos na gestão da educação pública superior constitui fator chave para os gestores destas instituições. Conhecer os custos é relevante para medir a eficiência de uma gestão, para o controle, e para a tomada de decisões sobre alocação de recursos. Dentre os custos que as IFES possuem estão os custos com transporte coletivo intermunicipal de pessoas, o qual é realizado através do uso de veículos próprios, ou através da terceirização do serviço. O objetivo do artigo é desenvolver um modelo de simulação computacional para avaliar cenários acerca da viabilidade econômica da terceirização do serviço de transporte coletivo intermunicipal de passageiros em IFES, a fim de auxiliar os gestores na decisão de utilizar veículos próprios ou terceirizar o serviço. O método utilizado foi a dinâmica de sistemas, com a utilização da modelagem computacional, e simulação de quatro cenários: cenário atual, no qual $20 \%$ da demanda de viagens é terceirizada, cenário possivel, no qual $50 \%$ da demanda de viagens é terceirizada, cenário teste, no qual $0 \%$ da demanda de viagens é terceirizada, e cenário hipotético, no qual $100 \%$ da demanda de viagens é terceirizada. Os resultados indicam que, ao longo de um período de 10 anos, em termos financeiros, o cenário hipotético representa a melhor opção, enquanto que o cenário teste representa o pior cenário. Os custos acumulados ao final dos 10 anos no cenário hipotético representam um valor $9,56 \%$ menor que os custos acumulados no cenário teste, $7,65 \%$ menor que os custos acumulados no cenário atual, e 4,78\% menor que os custos acumulados no cenário possível. Com isso, identificou-se que a terceirização do transporte de passageiros é viável economicamente, possibilita redução de custos a curto, médio e longo prazo, e demonstrou ser uma alternativa para melhorar a gestão de recursos públicos.

Palavras-chave: Terceirização; Modelagem Computacional; Custos.

\section{Evaluation of scenarios about the transport of people in an higher education institution: outsourcing versus use of own vehicles}

The modernization and expansion of higher education in Brazil required the use of best practices, increased efficiency and effectiveness by the Federal Institutions of Higher Education (IFES). In this sense, the measurement of costs in the management of public higher education is a key factor for the managers of these institutions. Knowing the costs is relevant to measure the efficiency of a management, to control, and to make decisions about resource allocation. Among the costs that IFES have are the costs of intercity collective transportation of people, which is carried out through the use of its own vehicles, or through outsourcing the service. The objective of the article is to develop a computer simulation model to evaluate scenarios about the economic feasibility of outsourcing the intercity passenger transport service in IFES, in order to assist managers in the decision to use their own vehicles or outsource the service. The method economic feasibility of outsourcing the intercity passenger transport service in IFES, in order to assist managers in the decision to use their own vehicles or outsource the service. The method
used was system dynamics, using computational modeling, and simulation of four scenarios: current scenario, in which $20 \%$ of travel demand is outsourced, possible scenario, in which $50 \%$ of travel demand is outsourced, test scenario, in which $0 \%$ of travel demand is outsourced, and hypothetical scenario, in which $100 \%$ of travel demand is outsourced. The results indicat that, over a period of 10 years, in financial terms, the hypothetical scenario represents the best option, while the test scenario represents the worst scenario. The costs accumulated at the end of 10 years in the hypothetical scenario represent a value $9.56 \%$ less than the costs accumulated in the test scenario, $7.65 \%$ less than the costs accumulated in the current scenario, and $4.78 \%$ less than the accumulated costs in the possible scenario. With that, it was identified that the outsourcing of passenger transport is economically viable, allows cost reduction in the short, medium and long term, and has proved to be an alternative to improve the management of public resources.

Keywords: Outsourcing; Computational modeling; Costs.

Topic: Pesquisa Operacional

Reviewed anonymously in the process of blind peer.

Fernando Negrini

Universidade Federal de Santa Maria, Brasil

http://lattes.cnpq.br/7697487215421797

negrinifnd@hotmail.com

Alexsandra Matos Romio (ii)

Universidade Federal de Santa Maria, Brasi

http://lattes.cnpq.br/5114024839768228

http://orcid.org/0000-0002-8001-065X

ale.matosr@gmail.com

Eugênio de Oliveira Simonetto (id

Universidade Federal de Santa Maria, Brasil

http://lattes.cnpq.br/1853313255345200

http://orcid.org/0000-0001-7572-5338

eosimonetto@gmail.com
Received: 07/04/2021

Approved: 04/06/2021

\author{
Debora Bobsin (10) \\ Universidade Federal de Santa Maria, Brasi \\ http://lattes.cnpq.br/9741757650191659 \\ http://orcid.org/0000-0001-6010-3958 \\ deborabobsin@gmail.com
}

Referencing this:

NEGRINI, F.; ROMIO, A. M.; SIMONETTO, E. O.; BOBSIN, D.. Avaliação de cenários acerca do transporte de pessoas em uma instituição de ensino superior: terceirização versus utilização de veículos próprios. Revista Brasileira de Administração Científica, v.12, n.2, p.273-289, 2021. DOI: http://doi.org/10.6008/CBPC2179-684X.2021.002.0022 


\section{INTRODUÇÃO}

Ao longo das últimas décadas, a gestão pública tem passado por alterações em sua estrutura, se adaptando às exigências da sociedade quanto à entrega de resultados, qualidade do serviço, redução de gastos, transparência e responsabilização (CAMPOS et al., 2020). Há pressões da sociedade para mais e melhores serviços, e melhor atendimento das demandas sociais da população, pelo uso eficiente de recursos e transparência dos atos (MOTTA, 2013). Neste contexto, estão inseridas as Instituições Federais de Ensino Superior (IFES), cuja gestão torna-se cada vez mais desafiadora devido à complexidade da missão e das características destas organizações (ANDRADE, 2002), às crescentes exigências da sociedade, à limitação de recursos (CAMARA et al., 2020), e ao seu papel fundamental para o desenvolvimento econômico e social do país (MAGALHÃES et al., 2010).

A modernização e expansão do ensino superior no Brasil exigiu o uso de melhores práticas, aumento de eficiência e eficácia por parte das instituições de ensino (VENTURINI et al., 2010). Neste sentido, a mensuração dos custos na gestão da educação pública superior constitui fator chave para os gestores das IFES. Conhecer os custos é relevante para medir a eficiência de uma gestão, para o controle, e para a tomada de decisões sobre alocação de recursos (MAGALHÃES et al., 2010). Dentre os custos que as IFES possuem estão os custos com transporte coletivo intermunicipal de pessoas, o qual é realizado através do uso de veículos próprios, ou através da terceirização do serviço. O transporte de pessoas é um instrumento para viabilizar a participação da comunidade acadêmica em atividades de ensino, pesquisa, e extensão, como aulas de campo, visitas técnicas, participação em eventos científicos e extensionistas, feiras técnicas, dentre outras (BARRETO et al., 2019). Conforme Aarão (2016), as IFES, a exemplo de Universidades e Institutos Federais de Educação, vêm presenciando crescente demanda por viagens, sejam elas acadêmicas, administrativas, ou mesmo políticas, decorrentes do aumento do número de vagas para discentes resultantes do PROUNI. Com isso, os gestores públicos têm que escolher dentre as alternativas disponíveis, aquela que representa o melhor emprego dos recursos financeiros, e que maximize a eficiência e eficácia da prestação destes serviços (ALBUQUERQUE JUNIOR, 2018).

Uma das alternativas para tentar diminuir os custos operacionais é a terceirização do serviço de transporte de pessoas. Alguns estudos, como os realizados por Braz et al. (2020), Albuquerque Junior (2018), e Aarão (2016), identificaram que a terceirização do serviço de transporte de passageiros em instituições de ensino resultou em redução de custos, em comparação com a utilização de veículos próprios. Porém, no trabalho de Souza (2017), constatou-se que a terceirização de transporte de passageiros teve custos operacionais mais elevados que a utilização de veículos próprios, que não a torna vantajosa economicamente. $\mathrm{O}$ uso da terceirização exige cautela, pois seu uso inadequado e a não observância do planejamento e dos preceitos legais pode acarretar no não cumprimento dos seus objetivos (SOUZA, 2017).

A utilização de modelagem de sistemas e da pesquisa operacional para simular e avaliar cenários tem sido utilizada para apoiar gestores na tomada de decisão em instituições públicas de ensino superior, a exemplo de descarte de lixo eletrônico (SCHNEIDER et al., 2015), utilização de biodiesel em tratores 
(RODRIGUES et al., 2017), e reaproveitamento de toners e cartuchos de impressoras (HUANG et al., 2012). Porém, não foram encontrados trabalhos voltados à simulação de cenários acerca da viabilidade econômica da terceirização de transporte intermunicipal de pessoas em IFES.

O objetivo do artigo é desenvolver um modelo de simulação computacional para avaliar cenários acerca da viabilidade econômica da terceirização do serviço de transporte coletivo intermunicipal de passageiros em Instituições Federais de Ensino Superior. Através da construção deste modelo, espera-se auxiliar os gestores no processo de tomada de decisão, em relação à terceirização, ou não, do transporte intermunicipal de passageiros, de forma a minimizar os custos gerados na utilização deste serviço. Assim, os gestores tomarão decisões pautadas no uso consciente e otimizados dos recursos, indo ao encontro da Lei de Responsabilidade Fiscal, que prevê o controle de gastos.

O trabalho está organizado da seguinte forma: a primeira seção contém a introdução com a contextualização e o objetivo do trabalho; na segunda seção é apresentada a revisão teórica, com os tópicos que forneceram embasamento para as análises e discussões; na terceira seção é apresentada a metodologia para o desenvolvimento do estudo. A quarta seção contém os resultados, seguido pela seção da discussão, que contém as análises, e por fim, a sexta seção contém as considerações finais, limitações e sugestões de estudos futuros.

\section{REVISÃO TEÓRICA}

\section{Terceirização}

A terceirização alcança, atualmente, diversos setores e é um fenômeno que se espalha rapidamente pelo mundo inteiro, sendo um fenômeno recente, que surgiu nos Estados Unidos, antes da segunda guerra mundial (SERRA, 2004). Conforme Prado (2005), a terceirização se caracteriza como uma técnica de gestão, que leva a mudanças estruturais e culturais na organização, significando mais que simplesmente cortar custos. Ela representa um tema importante e atual, que agrega valor aos negócios da organização e constitui uma estratégia chave para a alta administração da empresa.

O conceito de terceirização é definido por Pagnoncelli (1993) como "um processo planejado de transferência de atividades para serem realizadas por terceiros". O autor explica que é um "processo" porque é contínuo, permanente; é planejado, porque implantar um programa de terceirização sem considerar o planejamento estratégico é um erro que poderá comprometer o programa; atividades referem-se às ações que não sejam o âmago da missão da empresa; e realizada por terceiros, porque são executadas fora da empresa. Giosa (1997), define a terceirização como "a tendência de transferir, para terceiros, atividades que não fazem parte do negócio principal da empresa".

Serra (2004) cita vantagens e desvantagens da terceirização. Dentre as vantagens, a autora menciona a melhoria da qualidade dos serviços, a possibilidade de transferência de tecnologia sem custos extras, a diminuição dos custos fixos e variáveis da empresa, a maior facilidade de controle de custos pelo contratante, a focalização dos negócios da empresa em sua área de vocação, a limitação de risco de obsolescência de 
equipamentos e a redução do custo de estoques. Em relação às desvantagens, Serra (2004) cita a dificuldade de encontrar um parceiro ideal, o obstáculo de formular contratos de parceria, a tribulação de controle de contratos, a dificuldade no controle do custo interno com a empresa parceira, e a escolha de fornecedores não qualificados que reduzem a qualidade do produto/serviço.

A tomada de decisão pela terceirização, por parte das organizações, possui muitas razões e motivações. Bergamaschi (2004) cita que os motivadores para a terceirização podem ser diversos, mas são fundamentalmente de origem econômica, técnica ou estratégica. Dentre as principais motivações, apresentadas pelo autor, estão a redução de custos, a melhoria da qualidade dos serviços, e o foco em atividades relacionadas às competências essenciais da organização. As razões para terceirizar podem ser explicadas pelas vantagens oferecidas por fornecedores externos, que possuem equipamentos e tecnologias mais eficientes, especialização e foco nas suas atividades, além da obsolescência precoce de equipamentos e tecnologias.

O crescimento dos acordos de terceirização, em termos de porte e importância, tem gerado uma crescente preocupação com os riscos envolvidos no processo. Prado (2005) elenca os principais fatores de risco envolvendo terceirização: elaborar contratos incompletos, permitir um gerenciamento passivo por parte do fornecedor, deixar de construir e manter habilidades e capacidades internamente, construir acordos com pouca flexibilidade para se adaptar à rápida mudança no ambiente tecnológico e de negócios, gerenciar acordos de terceirização total, tendo pouca experiência no processo, e terceirizar com o objetivo de efetuar uma reestruturação financeira de curto prazo.

Para Preusler et al. (2015), a terceirização pode ser utilizada tanto por organizações privadas quanto por organizações públicas. Segundo os autores, da mesma forma que empresas privadas terceirizam em busca de uma maior eficiência nas atividades meio, podendo dedicar-se com mais afinco às atividades fim, as organizações públicas também passaram a utilizar essa forma de administração, que ainda contribuiu para a redução da burocracia estatal.

Serra (2004) salienta que a terceirização está presente durante todo processo produtivo, não ficando restrita a serviços, atingindo a condição de participação conjunta na atividades-fim do processo produtivo de empresas de vários países, inclusive o Brasil, por isso é importante que a legislação brasileira se adapte a esta realidade. Em seu estudo, Prado (2005) constatou que, em relação ao grau de formalidade dos arranjos contratuais de serviços terceirizados de tecnologia da informação (TI), 81,3\% dos arranjos são implantados através de contratos formais, enquanto os demais $18,7 \%$ de arranjos, sem contratos formais. Estes contratos sem formalização e sem definição de obrigações e direitos, geralmente adotados na contratação de serviços por demanda, a exemplo da manutenção de hardware, mostram que as alianças e parcerias realizadas com maior intensidade por empresas com cultura de terceirização são mais baseadas em confiança do que em contratos formais.

Apesar disso, a contratação de serviços terceirizados requer um cuidado especial. Conforme Cristofoli (2011), o processo de preparação e criação de um contrato de terceirização de serviços de TI deve ser exaustivo e completo, podendo, em alguns casos, ser extremamente complexo por envolver em um único 
contrato aspectos como o fornecimento dos serviços, transferência de infraestrutura de hardware e software, bem como a de funcionários. Os contratos devem especificar os acordos e termos firmados entre as partes para o cumprimento das trocas econômicas e não será completo se não abranger as obrigações das partes envolvidas em todas as situações (CRISTOFOLI, 2011).

\section{Custos}

Conhecer custos é uma condição essencial para administrar qualquer organização, independentemente do tipo e do porte, assim como exercer um melhor controle sobre as finanças. $\mathrm{O}$ custo está inserido na vida de todo indivíduo desde o nascimento até sua morte, uma vez que todos os bens e serviços necessários a seu consumo ou sua utilização têm um custo (DUTRA, 2009). Tratando-se de organizações, os custos resultam de uma combinação de diversos fatores, entre os quais estão a capacitação tecnológica e produtiva relativa a processos, e a qualificação de mão de obra. De modo geral, reflete nos custos uma série de variáveis, tanto interna quanto externas. Entre as variáveis internas estão o modo de operar, os comportamentos e atitudes, e dentre as externas incluem-se o nível de demanda e os preços dos insumos (MEGLIORINI, 2007).

O conceito de custo é definido por Dutra (2009) como "a parcela do gasto que é aplicada na produção ou em qualquer outra função de custo, gasto esse desembolsado ou não. Custo é o valor aceito pelo comprador para adquirir um bem ou é a soma de todos os valores agregados ao bem desde sua aquisição, até que ele atinja a comercialização". Para Bruni (2010), os custos correspondem aos gastos relativos a bens e serviços utilizados na produção de outros bens e serviços. Portanto, estão associados aos produtos e serviços utilizados pela entidade e representam uma transição de um investimento que tem como destino o valor dos estoques. Como exemplos, o autor cita gastos com matérias-primas, embalagens, mão de obra, aluguéis, seguros, entre outros. De forma semelhante, Megliorini (2007) afirma que custos correspondem à parcela dos gastos consumida no ambiente fabril para a fabricação do produto, pela aquisição de mercadorias para revenda e para a realização de serviços.

Dutra (2009) cita a diversidade de classificação dos custos, que variam quanto à natureza do objeto, quanto à apuração, quanto à formação, dentre outras classificações. Quanto à natureza, os principais tipos são: matérias-primas, mão de obra, energia elétrica, combustíveis, seguros, encargos sociais, aluguéis e manutenção. No que tange à apuração, os custos se classificam entre custos diretos (aqueles que podem ser diretamente apropriados a cada tipo de bem ou órgão no momento da sua ocorrência) e custos indiretos (aqueles que não podem ser apropriados diretamente a cada tipo de bem ou função no momento da sua ocorrência).

Já em relação à formação, os custos são classificados em fixos (custos de estrutura que ocorrem período após período sem variações, ou cujas variações não são consequência de variações do volume de atividades em igual período) e custos variáveis (variam em função da variação do volume de atividade, ou seja, da variação da quantidade produzida no período). Outro tipo de custo presente na atividade administrativa e que deve ser considerado pelos gestores é o custo de oportunidade. Conforme Bruni (2010), 
custos de oportunidade correspondem a gastos implícitos, inerentes à decisão, mas que, geralmente, não apresentam desembolsos efetivos. São apresentados como custos da alternativa preterida e devem ser formalmente considerados, ainda que não exista nenhum desembolso efetivo.

Considerando que um dos principais fatores que interferem na decisão das organizações entre "comprar ou fazer" é o fator econômico, conforme menciona Bergamaschi (2004), o estudo dos custos de transação tem sido amplamente utilizado em trabalhos envolvendo terceirização. A Teoria do Custo de Transação (TCT) representa a visão na qual os membros de uma organização tomam decisões de terceirização com base em razões econômicas. Williamson (1975), autor da TCT, coloca que os custos se originam de duas fontes: (1) custos de produção, que estão relacionados com material, capital e trabalho; e (2) os custos de coordenação, que são relacionados com planejamento, adaptação e monitoração das atividades. A TCT apresenta um modelo baseado em tipos de transações, na qual é indicado, para cada tipo de transação, a alternativa mais eficiente, ou seja, terceirizar - mercado - ou fazer internamente - hierarquia (PRADO, 2005).

Os custos de transação se relacionam aos custos de má adaptação, quando as transações não estão alinhadas ao que foi estabelecido em contrato; aos custos de negociação, nas situações em que cliente e fornecedores realizam esforços para resolver questões que não estão alinhadas; aos custos de configuração e condução das estruturas de governança, através das quais as disputas são resolvidas; e aos custos de ligação à efetividade dos comprometimentos estabelecidos pelos atores (WILLIAMSOM, 1996). A TCT considera que as características comportamentais dos agentes envolvidos nas transações podem afetar os tipos de contratos existentes e a decisão por um ou outro tipo de estrutura de governança utilizada. Dentre as características dos agentes econômicos envolvidos nas transações econômicas, a TCT destaca a racionalidade limitada e o oportunismo (WILLIAMSON, 1996).

\section{METODOLOGIA}

Para atingir o objetivo proposto, utilizou-se o método de modelagem computacional, caracterizado por modelos prescritivos. Modelos permitem a compreensão do ambiente em questão, a identificação dos problemas, a interpretação de estratégias, a análise de oportunidades, e culminam em uma tomada de decisão mais assertiva (MORABITO et al., 2010). Através do processo de modelagem, pode-se simular e imitar o comportamento de, praticamente, qualquer tipo de operação ou processo do mundo real (LAW et al., 1991). Simonetto et al. (2014) relatam que uma das principais etapas de um estudo de simulação consiste na criação de um modelo lógico, o qual consiste em um conjunto de suposições e aproximações, devidamente quantificadas e estruturadas, que visam representar o comportamento do sistema real sob determinadas condições. Modelos quantitativos participam do processo decisório partindo da relação causal e quantitativa do conjunto de variáveis de controle, que oscilam em um domínio específico, e variáveis de desempenho incorporadas ao modelo.

Conforme Simon (1996), a Modelagem de Sistemas pode ser classificada em predição ou prescrição. A predição consiste em tentar antecipar ou prever o futuro, enquanto que a prescrição se refere a uma sugestão de possíveis cenários, nos quais é possível tomar decisões para situações futuras. No modelo 
matemático computacional proposto por esse estudo, aplicou-se a prescrição, a fim de promover maior possibilidade de acertos diante dos cenários expostos.

Para o desenvolvimento do modelo, seguiu-se as etapas apresentadas por Law et al. (1991), conforme a seguir: 1. Inicialmente, buscou-se por modelos e métodos para análise de terceirização do serviço de transporte intermunicipal de passageiros em Instituições de Ensino Superior, consulta a trabalhos científicos, a dados de instituições, constantes em seus sítios eletrônicos, assim como a manuais de referência, portarias, licitações e dados da instituição que serviu de referência para a simulação do modelo, compondo a etapa de estudos exploratórios sobre o tema e o problema de pesquisa. Com isso, estruturouse e caracterizou-se o problema, viabilizando a elaboração do modelo conceitual a partir da avaliação de quais variáveis devem ser incorporadas ao escopo, bem como sua relação causal. Verificou-se a interação entre as variáveis, analisando se as mesmas delimitam o problema, e representam de forma sistematizada e simplificada a situação real, conforme sugerem Dresh et al. (2015), Law et al. (1991), Morabito et al. (2010) e Simon (1996); 2. Na segunda etapa, o modelo matemático formal foi estabelecido, com base na construção de soluções possíveis, e na formulação de suas equações básicas, aplicando e submetendo as variáveis que caracterizam o problema; 3. Na terceira etapa, ocorreu a implementação computacional da solução, com a sistematização do modelo matemático formal em um simulador. Neste trabalho, utilizou-se o simulador Vensim, desenvolvido pela Ventana Systems, da área de System Dynamics; 4. Por fim, os testes de alinhamento entre a realidade observada, representada pela instituição que serviu de referência, e os resultados obtidos no simulador foram executados, verificando a validação do modelo matemático e computacional por meio da simulação experimental de quatro cenários.

O modelo observa a variação dos custos por quilômetro rodado no transporte intermunicipal de passageiros, realizado com veículos do tipo ônibus, com capacidade para 40 lugares, em quatro cenários: terceirização de $20 \%$ do transporte de passageiros; 2 ) terceirização de $50 \%$ do transporte de passageiros; 3 ) terceirização de $0 \%$ do transporte de passageiros; 4) terceirização de $100 \%$ do transporte de passageiros.

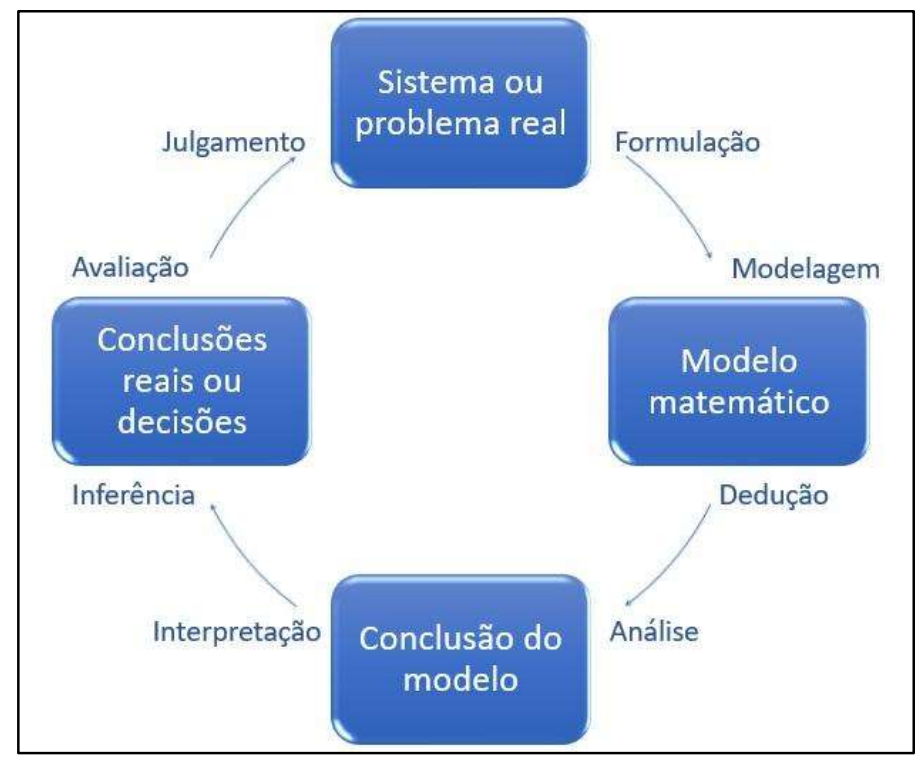

Figura 1: Processo de Modelagem. 
Nesse processo de modelagem matemática, utiliza-se o diagrama segundo Arenales et al. (2011), conforme Figura 1, no qual se formula uma hipótese que possibilite visualizar, o mais próximo da realidade, a dinâmica interna como consequência da estrutura do sistema, através da interação entre as variáveis e os pressupostos representados no modelo (ARENALES et al., 2011; LAW, 2013). Com base nisso, a hipótese dinâmica de Sistema Dinâmico pode ser desenhada com a associação da variável custos de transporte, influenciando diretamente a quantidade total destes. O problema real deste estudo aborda o processo decisório sobre a terceirização, ou a utilização de veículos próprios, do serviço de transporte coletivo intermunicipal de passageiros. O modelo matemático envolverá as variáveis relacionadas aos custos e à demanda de quilometragem para realização do transporte intermunicipal de pessoas.

O modelo foi desenvolvido, verificado e validado, com a utilização de dados reais coletados em uma IFES localizada no estado do Rio Grande do Sul, através da realização de simulações considerando diferentes cenários. O modelo proposto pode ser aplicado e estendido a outras organizações, de diferentes tipos e setores de atuação, desde que as especificidades do caso sejam adicionadas e tratadas no modelo.

\section{RESULTADOS}

$\mathrm{Na}$ análise documental, em que se procura a melhor delimitação e formulação do problema, identificou-se que o transporte intermunicipal de passageiros nas IFES é realizado em parte com a utilização de veículos próprios, e em parte com a contratação de empresas terceirizadas (AARÃO, 2016; ALBUQUERQUE JUNIOR, 2018; BARRETO et al., 2019). Assim, considerou-se que, para a realização do transporte coletivo intermunicipal de passageiros, existem variáveis relacionadas com a demanda de quilometragem e variáveis relacionadas aos custos. Conforme Figura 2, as variáveis referentes aos custos estão vinculadas aos custos com a terceirização do transporte, e aos custos com a utilização de veículos próprios para a realização do transporte. Em relação aos custos do transporte com a utilização de veículos próprios, estes se dividem em custos fixos e custos variáveis (AARÃO, 2016; ALBUQUERQUE JUNIOR, 2018).

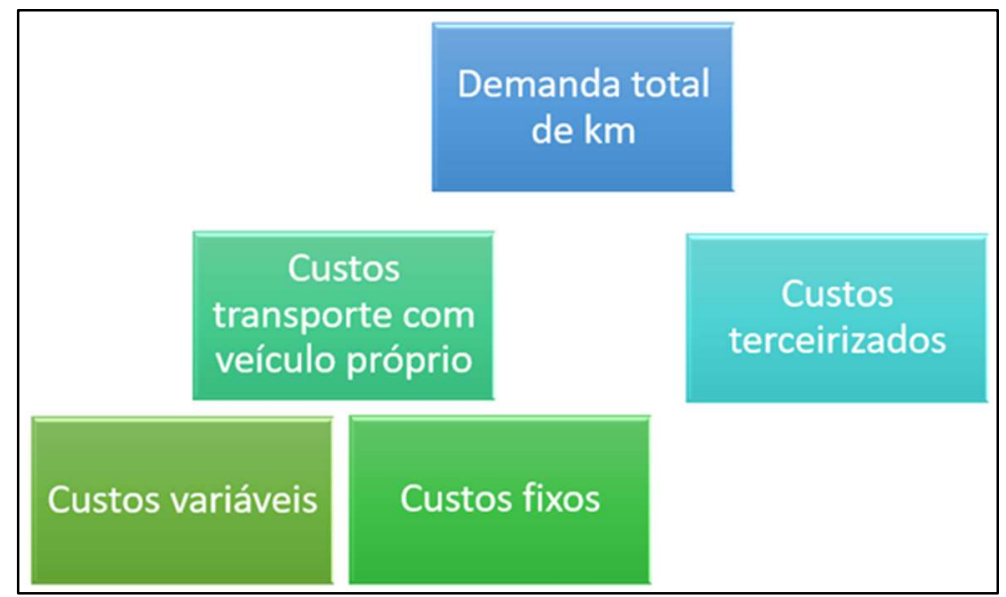

Figura 2: Etapa inicial de Modelagem.

Com base nos dados da IFES que serviu de referência para o desenvolvimento do modelo, elaborouse uma relação dos valores médios dos custos referentes às viagens realizadas com veículos próprios, ônibus com capacidade para 40 lugares, os quais são necessários para determinar a relação entre as variáveis do 
modelo matemático computacional, conforme a Figura 3. Na IFES que serviu de referência para a simulação do modelo desenvolvido, o inventário de bens móveis indica que a instituição possui 3 ônibus próprios, com capacidade de 40 lugares, os quais necessitam de manutenção, combustíveis, lubrificantes, dentre outros custos. A instituição também utiliza o serviço de locação de ônibus para o transporte intermunicipal de passageiros, que inclui as despesas com diárias, alimentação, salário, encargos trabalhistas, previdenciários e seguro, o qual é prestado por uma empresa terceirizada.

Para que o modelo possa ser replicado em qualquer instituição, utiliza-se as informações listadas conforme os custos médios estabelecidos no próprio modelo, ou alteram-se as variáveis conforme necessidades específicas.

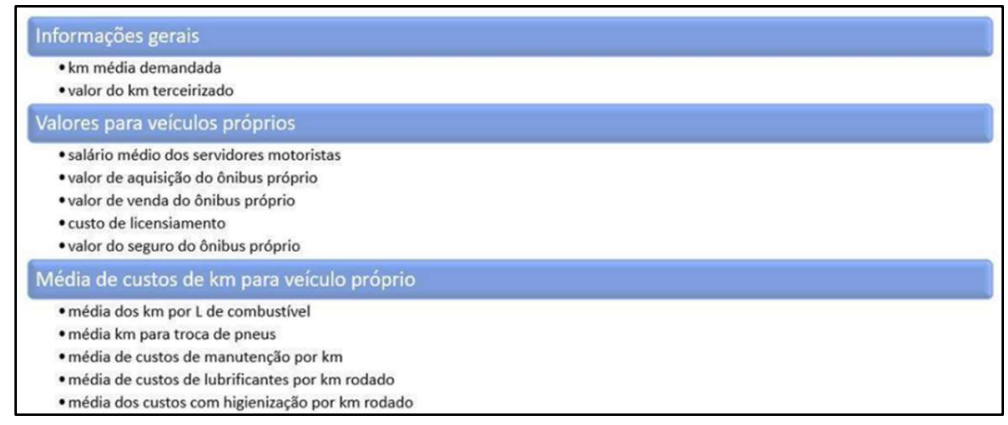

Figura 3: Lista de informações que limitam o modelo.

Dessa forma, o modelo foi concebido de acordo com o mapa da Figura 4, o qual estabelece as relações entre as variáveis e as implicações entre elas. A ideia central corresponde em dividir a quilometragem demandada entre as alternativas de terceirização do serviço de transporte de passageiros, e a utilização de veículo próprio para realização do transporte, com o objetivo de estabelecer diferentes cenários. Foram estabelecidos quatro cenários: 1) terceirização de $20 \%$ da demanda, que corresponde ao cenário atual; 2) terceirização de $50 \%$ da demanda, que corresponde ao cenário possível; 3) terceirização de 0\%, que corresponde ao cenário teste; e 4) terceirização de 100\%, que corresponde ao cenário hipotético, ou seja, transporte de passageiros feito unicamente com utilização de veículos próprios da instituição.

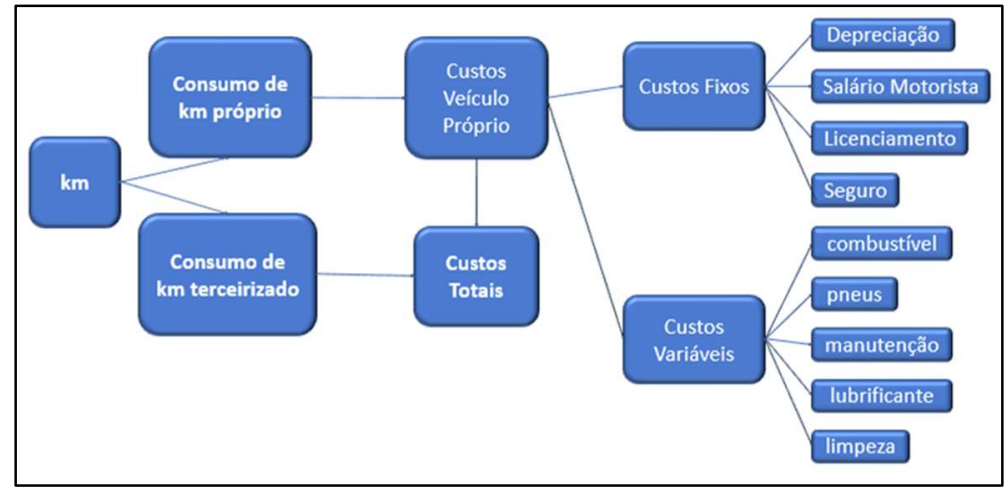

Figura 4: Mapa da concepção do modelo.

As variáveis e suas relações foram estabelecidas com a implementação computacional da solução, utilizando-se o simulador Vensim, da área de System Dynamics. Na Figura 5, é possível observar o modelo proposto, que conta com quatro variáveis do tipo estoque: somabusproprios, a qual soma as quilometragens 
definidas pelos cenários para a realização de viagens com veículo próprio, somaterceirizado, que representa a realização de viagens com terceirização de veículo, custoproprio, que soma os custos fixos e variáveis para realização de viagens com veículo próprio, e a variável custos, que representa a relação dos custos totais.

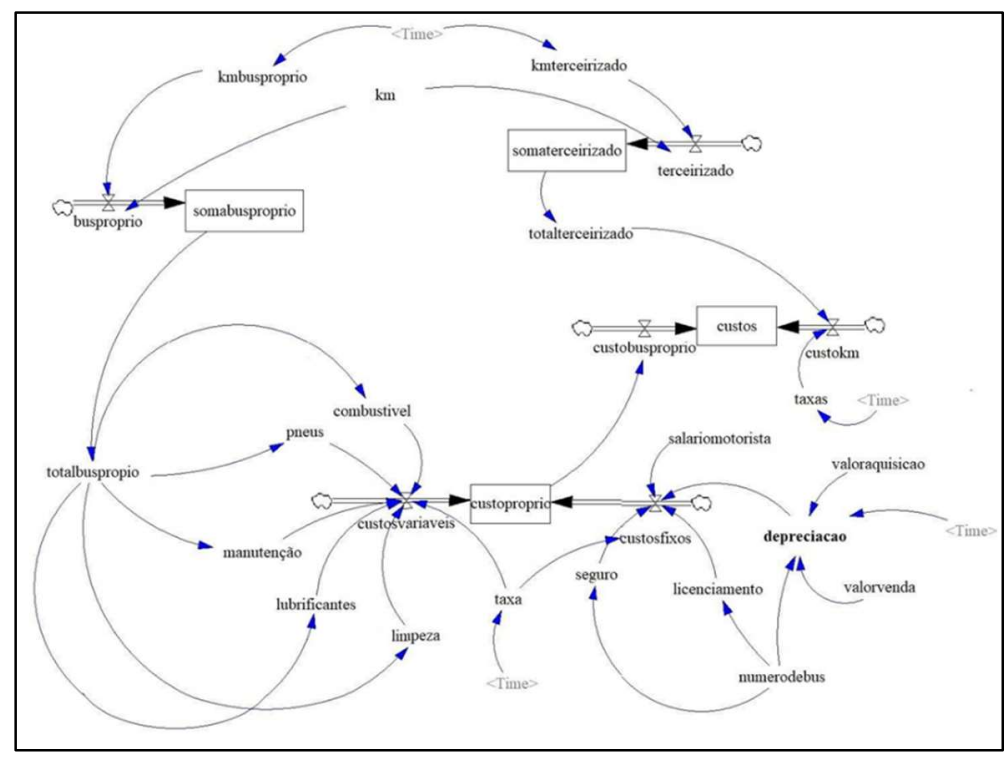

Figura 5: Modelo proposto.

O modelo possui 15 variáveis auxiliares: $\mathrm{km}$, a qual se refere à demanda de quilometragem; kmterceirizado, que indica à quilometragem de demanda terceirizada; kmbusproprio, que corresponde à quilometragem distribuída nos veículos próprios. Em relação aos custos fixos, tem-se as variáveis auxiliares: combustível, que representa o consumo de combustível por $\mathrm{km}$ rodado multiplicado pelo valor atual do diesel: pneus, que corresponde à necessidade de troca de pneus em relação ao km rodado, multiplicado pelo número de pneus e pelo valor de troca ou remodelagem; manutenção, que se refere aos gastos com oficina em concordância com o km rodado, e lubrificantes e limpeza. No que tange aos custos fixos para utilização de veículo próprio, estão relacionadas as variáveis auxiliares: seguro, licenciamento e depreciação, as quais são multiplicadas pela variável auxiliar numerodebus, que vai informar quantos veículos a IFES possui; a variável salariomotorista calcula a média dos valores da remuneração dos servidores motoristas; e a variável depreciação é obtida através do cálculo do valor de compra (valorcompra) menos o valor da venda do veículo próprio (valorvenda), dividido por 120 e multiplicado por 12, conforme apresentado por (BARRETO et al., 2019).

O modelo ainda possui quatro variáveis auxiliares especiais: totalbusproprio, a qual contempla o somatório da demanda de quilometragem distribuída para o veículo próprio; totalterceirizado, a qual apresenta o somatório da demanda de quilometragem distribuída ao serviço terceirizado. Essas variáveis (totalterceirizado e totalbusproprio) irão multiplicar os demais custos em relação ao transporte. No caso da totalbusproprio, vai ser a kilometragem total que multiplicará os custos variáveis e, para totalterceirizado, haverá a multiplicação do valor de referência para cada kilometragem de licitação, e duas taxas, taxa e taxas, que fazem referência ao aumento dos custos ao longo do tempo. Por fim, a shadow variable, chamada 'Time', a qual possibilita o armazenamento de alteração das variáveis com o passar dos anos, contemplando uma 
relação de aumento dos custos ao longo de um período de 10 anos, considerando os reajustes monetários.

Para o modelo matemático, as variáveis são calculadas conforme as Figuras 6 a 9. As Figuras 6 a 9 foram recortadas do modelo original para detalhar as equações incorporadas, e proporcionar melhor compreensão do modelo.

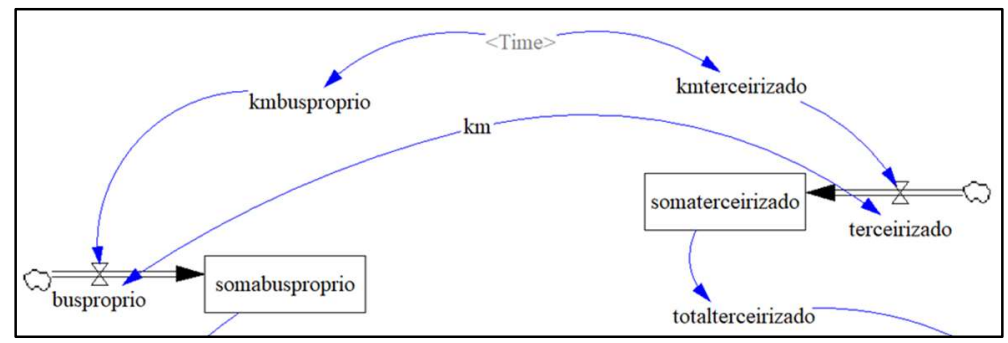

Figura 6: Recorte ampliado do modelo proposto - determinação dos cenários

Incorporadas ao modelo, as variáveis são matematicamente descritas conforme as equações:

busproprio $=$ kmbusproprio $\times \mathrm{km}$

terceirizado $=$ kmterceirizado $\times \mathrm{km}$

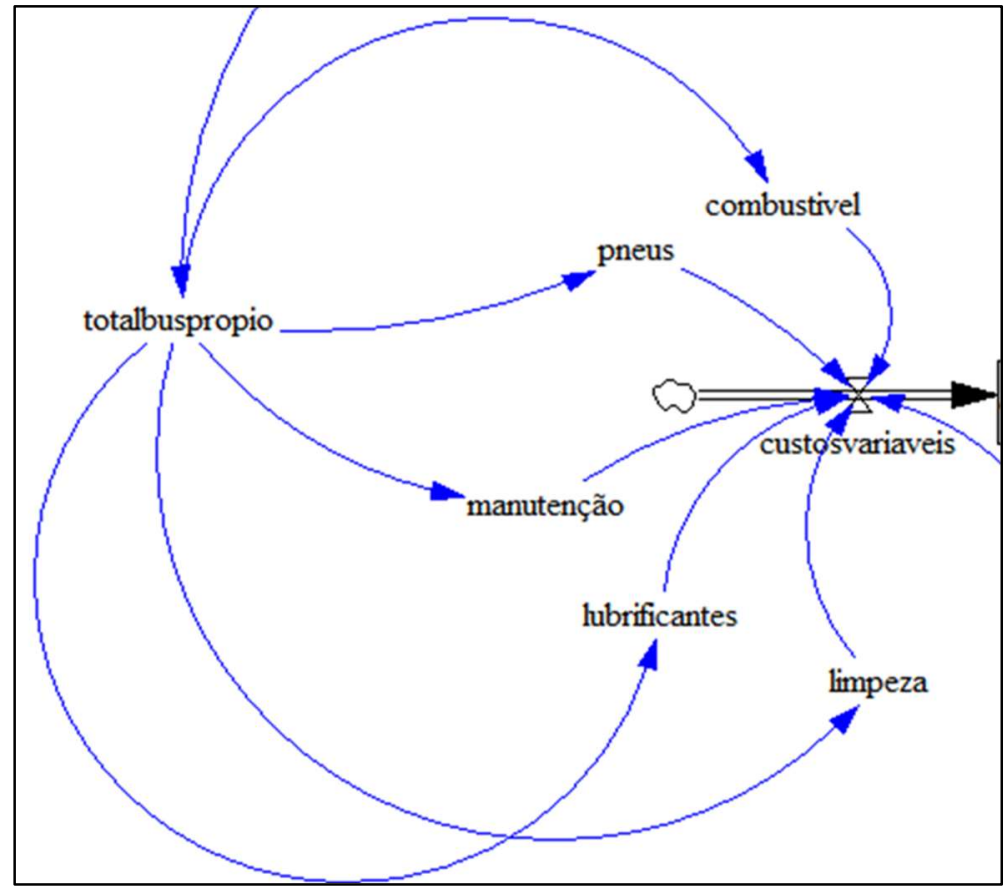

Figura 7: Recorte ampliado do modelo proposto - custos variáveis.

Na sequência, segue a descrição matemática incorporado ao modelo, conforme demonstra as equações:

$$
\begin{gathered}
\text { combustivel }=\left(\frac{\text { totalbusproprio }}{\text { consumo do ônibus }}\right) \times \text { valor do diesel } \\
\text { pneus }=\left(\frac{\text { totalbusproprio }}{\text { km de troca dos pneus }}\right) \times \text { número de pneus } \times \text { valor do pneu } \\
\text { manutencao }=\text { totalbusproprio } \times \text { custo da manutenção por } \mathrm{km} \\
\text { lubrificantes }=\text { totalbusproprio } \times \text { custo com lubrificante por } \mathrm{km} \\
\text { limpeza }=\text { totalbusproprio } \times \text { custo com higienização por } \mathrm{km}
\end{gathered}
$$

custosvariaveis $=($ combustivel + lubrificantes + limpeza + pneus + manutencao $) \times$ taxa 


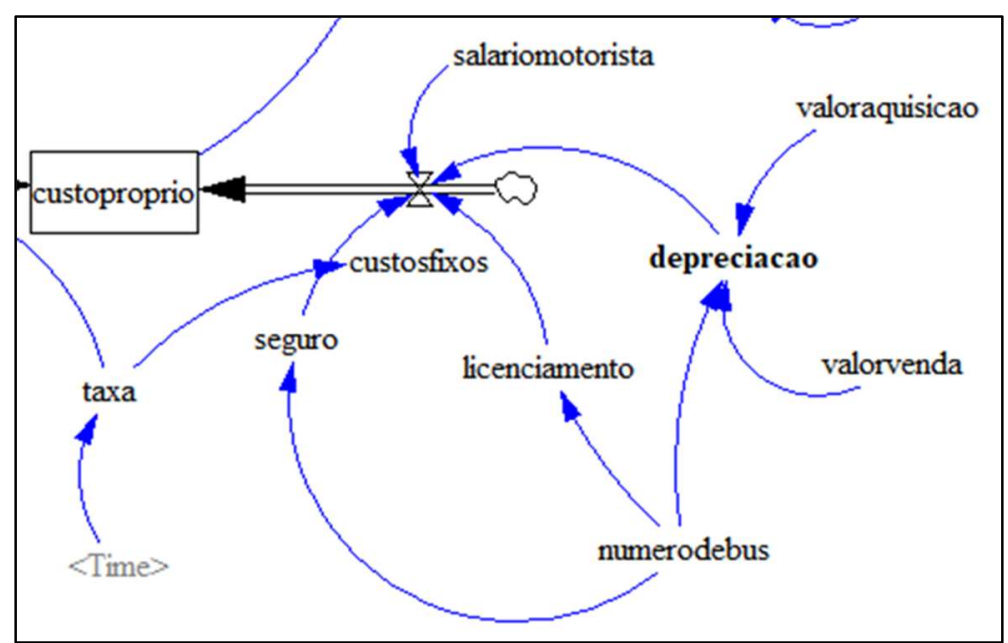

Figura 8: Recorte ampliado do modelo proposto - custos fixos.

Conforme as equações a seguir, é possível verificar as variáveis incorporadas ao modelo:

$$
\begin{gathered}
\text { depreciacao }=\left[\frac{(\text { valoraquisicao }- \text { valorvenda })}{120}\right] \times 12 \times \text { numerodebus } \\
\text { licenciamento }=\text { valor do licenciamento } \times \text { numerodebus } \\
\text { seguro }=\text { valor do seguro } \times \text { numerodebus } \\
\text { custosfixos }=(\text { depreciacao }+ \text { seguro }+ \text { licenciamento }+ \text { salariomotorista }) \times \text { taxa } \\
\text { custoproprio }=\text { custosfixos }+ \text { custosvariaveis }
\end{gathered}
$$

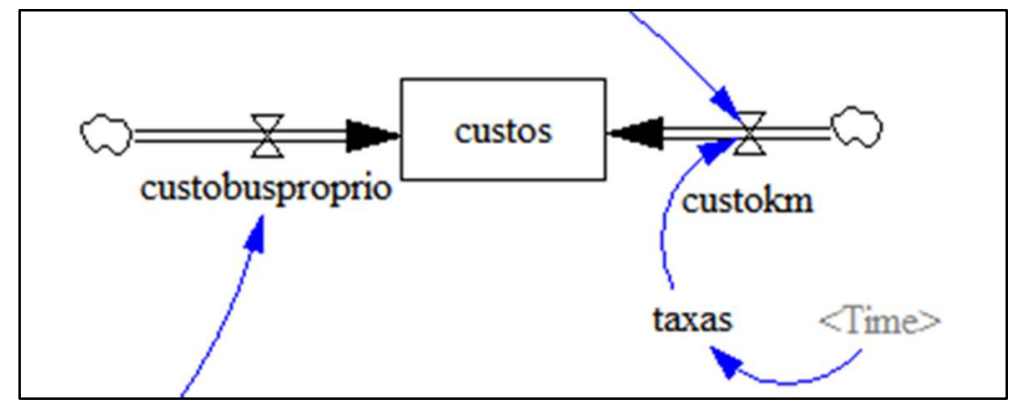

Figura 9: Recorte ampliado do modelo proposto - somatório dos custos.

Seguem abaixo as equações matemáticas referentes ao somatório dos custos:

$$
\begin{gathered}
\text { custokm }=\text { totalterceirizado } \times \text { taxas } \times \text { valorkm } \\
\text { custos }=\text { custokm }+ \text { custobusproprio }
\end{gathered}
$$

\section{DISCUSSÃO}

Para análise dos resultados, execução e validação do modelo foram utilizados dados de uma IFES localizada no Estado do Rio Grande do Sul, a fim de verificar os impactos econômicos que a utilização de veículos, próprios e terceirizados, terão para a realização de viagens intermunicipais, ao longo de um período de 10 anos. 0 estudo limitou-se a veículos do tipo ônibus, com 40 lugares, excluindo-se micro-ônibus, veículos leves e demais categorias de veículos. Foram desenvolvidos quatro cenários: Cenário atual, onde $20 \%$ da demanda de quilômetros realizadas é terceirizada; Cenário possível, onde $50 \%$ da demanda de quilômetros é terceirizada; Cenário teste, onde $0 \%$ da demanda de quilômetros é terceirizada. Este cenário foi 
estabelecido com o intuito de certificar-se que os valores atribuídos às variáveis correspondem aos valores gastos pela instituição da qual os dados foram coletados; Cenário hipotético, onde 100\% da demanda de quilômetros seria terceirizada.

Definidos os cenários, partiu-se para as simulações, com utilização de dados da Instituição que serviu de base para o estudo, e algumas informações estimadas com o cenário atual, como preço médio do diesel, tempo de reparo dos pneus e a demanda média de quilometragem. A instituição possui licitação válida para utilização de $50.000 \mathrm{~km}$ anuais de transporte rodoviário intermunicipal de passageiros, o qual é fornecido por uma empresa terceirizada, a um custo de $\mathrm{R} \$$ 6,00 por $\mathrm{km}$. A utilização do serviço de transporte intermunicipal executado pela empresa terceirizada, foi, em média, 35.454 km por ano, o que equivale a cerca de $28 \%$ de sua demanda total, que gira em torno de $128.000 \mathrm{~km}$ a cada ano. Essas médias são relativas aos últimos dois anos.

Considerou-se, como custo médio para o diesel, o valor de $\mathrm{R} \$$ 3,60, e em média, os ônibus pertencentes à IFES rodam $2,42 \mathrm{~km}$ com um litro de diesel. A manutenção dos veículos próprios custa $\mathrm{R} \$$ 3,14 por $\mathrm{km}$ rodado. Estes valores foram obtidos em relatórios fornecidos por servidores técnico administrativos da IFES. Os lubrificantes e a limpeza não estão contabilizados individualmente, já que estes custos estão incluídos nos custos de manutenção, mas estão no modelo para que possam ser aplicados em instituições que contabilizem estes custos de forma individualizada.

O seguro DPVAT foi estimado em $R \$ 1600,00$, enquanto que o licenciamento foi estimado em $R \$$

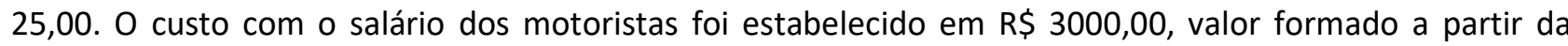
consulta à tabela de vencimentos do plano de carreira dos cargos técnico administrativo em educação, acrescido de um valor médio referente às diárias, as quais são pagas ao servidor público que se desloca à serviço para outras localidades. A depreciação foi calculada considerando os valores de compra, que está em torno de $\mathrm{R} \$ 180.000,00$, e de venda, em torno de $\mathrm{R} \$ 70.000,00$.

Através do demonstrativo de custos apresentados na Tabela 1, é possível visualizar os valores atuais e o aumento dos valores com o passar do tempo, em função dos reajustes monetários. Considerou-se um período de 10 anos para a avaliação dos cenários. As decisões dos gestores, a partir dos resultados gerados pelo modelo, envolvem a utilização de veículo pertencente à instituição para o transporte intermunicipal de pessoas, ou a terceirização do serviço de transporte intermunicipal, considerando quatro diferentes cenários. Entretanto, poderão ser estabelecidos novos cenários de simulação, de acordo com a necessidade ou disponibilidades de recursos dos gestores.

Tabela 1: Valores monetários em relação aos cenários e ao tempo.

\begin{tabular}{l|llll} 
& Cenário Atual & Cenário Possível & Cenário Teste & Cenário Hipotético \\
\hline & Terceirizado 20\% & Terceirizado 50\% & Terceirizado 0\% & Terceirizado 100\% \\
\hline Ano & Próprio 80\% & Próprio 50\% & Próprio 100\% & Próprio 0\% \\
\hline $\mathbf{1}$ & $\mathrm{R} \$ 890.918,00$ & $\mathrm{R} \$ 865.282,00$ & $\mathrm{R} \$ 908.008,00$ & $\mathrm{R} \$ 822.555,00$ \\
\hline $\mathbf{2}$ & $\mathrm{R} \$ 901.378,00$ & $\mathrm{R} \$ 877.813,00$ & $\mathrm{R} \$ 917.088,00$ & $\mathrm{R} \$ 838.537,00$ \\
\hline $\mathbf{3}$ & $\mathrm{R} \$ 918.896,00$ & $\mathrm{R} \$ 894.813,00$ & $\mathrm{R} \$ 934.952,00$ & $\mathrm{R} \$ 854.673,00$ \\
\hline $\mathbf{4}$ & $\mathrm{R} \$ 936.583,00$ & $\mathrm{R} \$ 911.975,00$ & $\mathrm{R} \$ 952.988,00$ & $\mathrm{R} \$ 870.963,00$ \\
\hline $\mathbf{5}$ & $\mathrm{R} \$ 954.438,00$ & $\mathrm{R} \$ 929.301,00$ & $\mathrm{R} \$ 971.196,00$ & $\mathrm{R} \$ 887.406,00$ \\
\hline $\mathbf{6}$ & $\mathrm{R} \$ 972.462,00$ & $\mathrm{R} \$ 946.790,00$ & $\mathrm{R} \$ 989.576,00$ & $\mathrm{R} \$ 904.003,00$ \\
\hline $\mathbf{7}$ & $\mathrm{R} \$ 990.654,00$ & $\mathrm{R} \$ 964.441,00$ & $\mathrm{R} \$ 1.008 .130,00$ & $\mathrm{R} \$ 920.753,00$ \\
\hline
\end{tabular}




\begin{tabular}{l|l|l|l|l}
\hline $\mathbf{8}$ & $\mathrm{R} \$ 1.009 .010,00$ & $\mathrm{R} \$ 982.255,00$ & $\mathrm{R} \$ 1.026 .850,00$ & $\mathrm{R} \$ 937.657,00$ \\
\hline $\mathbf{9}$ & $\mathrm{R} \$ 1.027 .540,00$ & $\mathrm{R} \$ 1.000 .230,00$ & $\mathrm{R} \$ 1.045 .750,00$ & $\mathrm{R} \$ 954.715,00$ \\
\hline $\mathbf{1 0}$ & $\mathrm{R} \$ 1.046 .240,00$ & $\mathrm{R} \$ 1.018 .370,00$ & $\mathrm{R} \$ 1.064 .820,00$ & $\mathrm{R} \$ 971.926,00$ \\
\hline
\end{tabular}

Ao longo dos 10 anos, o cenário hipotético, no qual 100\% do transporte coletivo de passageiros é terceirizado, representa a melhor opção em termos financeiros, totalizando um custo de $\mathrm{R} \$ 971.926,00$ no

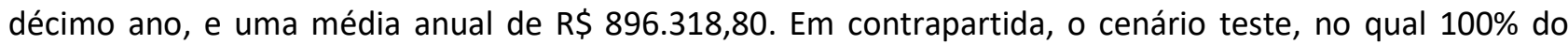
transporte é realizado com veículos próprios, representa o pior cenário em termos financeiros, gerando um custo de 1.046.240,00 no décimo ano, uma diferença de $\mathrm{R} \$$ 92.894,00. Os custos acumulados ao final dos 10 anos no cenário hipotético representam um valor 9,56\% menor que os custos acumulados no cenário teste, $7,65 \%$ menor que os custos acumulados no cenário atual, e 4,78\% menor que os custos acumulados no cenário possível.

Estes resultados corroboram estudos anteriores, que identificaram que o custo de transporte por km é menor com a utilização da frota de veículos terceirizada em uma Instituição Federal de Ensino (AARÃO, 2016), e que a locação de veículos representa economia de recursos em relação ao uso de veículos próprios (ALBUQUERQUE JUNIOR, 2018).

Apesar de representar a opção mais vantajosa em termos financeiros, a aplicação do cenário hipotético é improvável, pois acarretaria a ociosidade dos veículos do tipo ônibus que a instituição possui, além da perda de autonomia e flexibilidade na utilização dos veículos próprios. Este cenário também poderia acarretar a necessidade de alienação, cessão ou transferência destes bens móveis.

No cenário atual e no cenário possível, tem-se situações intermediárias, onde os gastos no final do período analisado são menores que no cenário teste, e maiores que no cenário hipotético. No cenário possível, onde $50 \%$ do transporte é realizado com frota própria, e $50 \%$ com frota terceirizada, tem-se uma economia de $\mathrm{R} \$ 27.870,00$ no final do décimo ano em relação ao cenário atual, configurando assim uma decisão mais vantajosa em termos de economicidade, e viável operacionalmente. A utilização de veículos próprio e terceirizados, simultaneamente, exigirá dos gestores maior capacidade de planejamento, pois na logística, além dos custos com transporte, deve-se considerar também a segurança, agilidade e outros aspectos de cunho não financeiro.

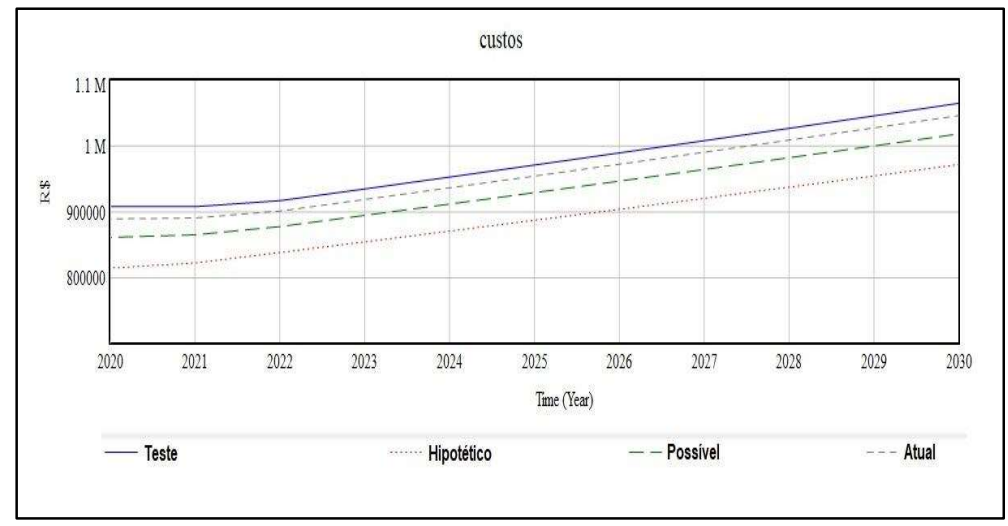

Figura 10: Custos ao longo do tempo.

A Tabela 1 e a Figura 10 demonstram que, os custos com transporte terceirizado são menores que 
os custos com veículos próprios desde o primeiro ano, mantendo-se menores em todos os anos analisados, como pode ser observado no cenário teste, e no cenário hipotético. Ao longo do tempo, com os reajustes e atualizações monetárias, os custos com o transporte próprio aumentam em função da depreciação e manutenção dos veículos, bem como do salário e adicionais dos motoristas, enquanto que os custos fixos são os mesmos, independentemente do cenário. Esta relação também pode ser observada quando se analisa o cenário atual e o cenário possível. Comparando-se o cenário atual com o cenário possível, este apresenta custos menores ao longo dos 10 anos analisados, sendo que, no final do décimo ano, obtém-se uma economia de $\mathrm{R} \$ 27.870,00$, o que representa $2,74 \%$.

Salienta-se que a adoção de qualquer um dos cenários propostos também dependem de outros fatores, como os objetivos e as metas do Plano de Desenvolvimento Institucional (PDI), a realização de licitação para a escolha da empresa terceirizada, e a cultura organizacional, os quais não foram considerados neste estudo, que se restringiu aos aspectos financeiros.

\section{CONCLUSÕES}

A mensuração dos custos é um fator chave para a gestão de qualquer organização, seja pública ou privada. Através do bom gerenciamento de custos torna-se mais fácil a adoção de melhores práticas de gestão e melhorar a eficiência organizacional. Um dos custos que as instituições federais de ensino possuem são os custos com transporte coletivo intermunicipal de pessoas, os quais são necessários para realização de viagens com fins de ensino, pesquisa, extensão ou atividades administrativas. Neste sentido, os gestores têm que tomar decisões visando a economicidade e o interesse público, e uma das decisões é a realização de transporte com veículos próprios da instituição, ou com veículos terceirizados.

Este trabalho teve como objetivo desenvolver um modelo de simulação computacional para avaliar cenários acerca da viabilidade financeira da terceirização do serviço de transporte de passageiros em Instituições Federais de Ensino Superior, a fim de auxiliar o gestor na tomada de decisão. O modelo desenvolvido considerou quatro cenários, e através da análise dos resultados identificou-se que o cenário hipotético, no qual $100 \%$ do transporte é feito com veículos terceirizados, é o que apresenta os menores custos ao longo dos 10 anos, representando uma economia de $\mathbf{R}$ 92.894,00 em relação ao cenário no qual se utiliza $100 \%$ de veículos próprios. Já no cenário possível, onde $50 \%$ do transporte é realizado com veículos próprios e 50\% com veículos terceirizados, tem-se uma economia de $\mathrm{R} \$ 27.879,00$ em relação ao cenário atual. Com isso, identificou-se que a terceirização do transporte de passageiros é viável economicamente, e possibilita redução de custos a curto, médio e longo prazo.

A principal contribuição prática deste estudo é o desenvolvimento de uma ferramenta que auxilia os gestores na tomada de decisão em relação à utilização de veículos próprios ou veículos terceirizados para o transporte coletivo intermunicipal de passageiros, visando economicidade, eficiência na gestão, otimização de recursos, e cumprimento das responsabilidades fiscais. O modelo também pode ser aplicado a diferentes tipos de organizações e a diferentes cenários, ampliando assim sua aplicabilidade.

Entre as limitações do estudo está a ausência de variáveis que deixariam o modelo mais preciso, a 
exemplo do índice de inflação, alguns tipos de manutenção e limpeza dos veículos, depreciação dos veículos, garagem, e adicionais aos motoristas. Outra limitação foi a falta de precisão de algumas variáveis, as quais foram calculadas utilizando a média de valores, e não valores exatos.

Como sugestões para pesquisas futuras recomenda-se ampliar os tipos de veículos abordados no modelo, abrangendo automóveis, micro-ônibus, além dos ônibus de 40 lugares, representando assim um conjunto mais completo da frota de veículos que uma IFES possui. Sugere-se também incluir outras variáveis ao modelo, tornando-o mais correto e apurado.

\section{REFERÊNCIAS}

AARÃO, L. R.. Terceirização versus frota própria: Uma análise da função transporte em uma instituição federal de ensino. Dissertação (Mestrado em Administração Pública) Universidade Federal de Viçosa, Viçosa, 2016.

ALBUQUERQUE JUNIOR, R.. Análise da terceirização de serviço de transporte no serviço público: um estudo comparativo. Dissertação (Mestrado em Políticas Públicas e Gestão da Educação Superior) - Universidade Tecnológica Federal do Paraná, Curitiba, 2018.

ANDRADE, A. R.. A universidade como organização complexa. Revista de Negócios, Blumenau, v.7, n.3, p.15-28, 2002.

ARENALES, M.; ARMENTANO, V. A.; MORABITO, R.; YANASSE, H. H.. Pesquisa operacional. Rio de Janeiro: Elsevier, 2011.

BARRETO, P. R.; JÚNIOR, M. E.; SOUZA, C. L. M.; GONÇALVES, M. M.; SOUZA, C. E.. Seleção de meio de transporte coletivo de estudantes aplicado a uma instituição de ensino. In: SIMPÓSIO DE PESQUISA OPERACIONAL E LOGÍSTICA DA MARINHA, 19. Anais. Rio de Janeiro, 2019.

BERGAMASCHI, S.. Modelos de gestão da terceirização de Tecnologia da Informação: um estudo exploratório. Tese (Doutorado em Administração) - Universidade de São Paulo, São Paulo, 2004.

BRAZ, E. T.; CHIQUIERI, J.; GONCALVES, W.. Método multicritério como ferramenta para auxílio na decisão sobre alternativa de uso de transporte. Brazilian Journal of Production Engineering, São Mateus, v.6, n.2, p.142-155, 2020.

BRUNI, A. L.. A administração de custos, preços e lucros. 4 ed. São Paulo: Atlas, 2010.

CAMARA, K. M. C.; CHIQUIERI, J.; GONÇALVES, W.. Orçamento público em um campus universitário: o Analytic Hierarchy Process no auxílio à tomada de decisão. Brazilian Journal of Production Engineering, São Mateus, v.6, n.2, p.128-141, 2020.

CAMPOS, M. C.; DANTAS, A. B.; MILITO, C. M.; SILVA, L. S. C. V.. Avaliação de maturidade em gestão de projetos na Universidade Federal de Alagoas utilizando o método PRADO-MMGP. Revista de Gestão e Projetos, São Paulo, v.11, n.1, p.1-16, 2020. DOI:

https://doi.org/10.5585/gep.v11i1.15870
CRISTOFOLI, F.. Um estudo sobre a terceirização de serviços de tecnologia da informação baseados em modelo de governança. Tese (Doutorado em Administração) Universidade de São Paulo, São Paulo, 2011.

DUTRA, R. G.. Custos: uma abordagem prática. São Paulo: Atlas, 2009.

DRESH, A.; LACERDA, D. P.; JÚNIOR ANTUNES, J. A. V.. Design Science Research: Método de Pesquisa para avanço da ciência e tecnologia. Porto Alegre: Bookman, 2015.

GIOSA, L. A.. Terceirização: uma abordagem estratégica. São Paulo: Pioneira, 1997.

HUANG, T. T.; SARTORI, V. S.. Estudo sobre remanufatura de cartuchos de toner de impressora de duas faculdades da UNICAMP. Revista Ciências do Ambiente, v.8, n.2, 2012.

LAW, A. M.; KELTON, W. D.. Simulation modeling and analysis. 2 ed. New York: McGraw-Hill, 1991.

LAW, A. M.. Simulation modeling and analysis. 15 ed. New York: McGraw-Hill, 2013.

MAGALHÃES, E. A.; SILVEIRA, S. F. R.; ABRANTES, L. A.; FERREIRA, M. A. M.; WAKIM, V. R.. Custo do ensino de graduação em instituições federais de ensino superior: 0 caso da Universidade Federal de Viçosa. Revista de Administração Pública, Rio de Janeiro, v.44, n.3, p.637-66, 2010. DOI: https://doi.org/10.1590/S003476122010000300005

MEGLIORINI, E.. Custos: análise e gestão. 2 ed. São Paulo: Pearson Prentice Hall, 2007.

MOTTA, P. R. M.. O estado da arte da gestão pública. Revista de Administração de Empresas, São Paulo, v.55, n.1, p.082090, 2013. DOI: https://doi.org/10.1590/S003475902013000100008

MORABITO, R.; PUREZA, V.. Modelagem e simulação. In: MIGUEL, P. A. C.. Metodologia de pesquisa em engenharia de produção e gestão de operações. Rio de Janeiro: Elsevier, 2010, p.165-194.

PAGNONCELLI, D.. Terceirização e parceirização: estratégia para o sucesso empresarial. Rio de Janeiro: D. Pagnoncelli, 1993. 
PRADO, E. P. V.. Tecnologia de Informação e Sistemas: uma avaliação da terceirização de serviços em organizações do setor privado. Tese (Doutorado em Administração) Universidade de São Paulo, São Paulo, 2005.

PREUSLER, T. S.; CRESPI, T. B.; MARAFON, D. L.; NARDI, V.. Terceirização dos serviços de impressão como forma de obtenção da ecoeficiência em uma empresa pública de pesquisa agropecuária. Revista Inovação, Projetos e Tecnologias - IPTEC, São Paulo, v.3, n.2, p. 238-253, 2015. DOI: http://dx.doi.org/10.5585/iptec.v3i2.41

RODRIGUES, G. O.; SCHNEIDER, J. R.; PEREIRA, A.; SIMONETTO, E. O.; LOBLER, M.; TREVISAN, M.. Proposto de utilização de biodiesel em tratores de uma instituição de ensino superior: uma simulação computacional. Estudos do CEPE, Santa Cruz do Sul, n.45, p.74-91, 2017. DOI: http://dx.doi.org/10.17058/cepe.v0i45.8248

SCHNEIDER, J. R.; ZWICKER, A. A. M.; BELTRAME, G.; SIMONETTO, E. O.. Simulação baseada em systems dynamics para avaliação de cenários sobre geração e disposição de resíduos eletrônicos numa instituição de ensino superior. In: SEMINÁRIOS EM ADMINISTRAÇÃO - SEMEAD, 18. Anais, São Paulo: FEA/USP, 2015.

SERRA, S. M. B.. Qualidade na terceirização. In: OLIVEIRA, O. J.. Gestão da qualidade: tópicos avançados. Cengage Learning: São Paulo, 2004. p.147-158.
SIMON, H. A.. The sciences of the artificial. 3 ed. Cambridge: MIT Press, 1996.

SIMONETTO, E. O.; LÖBLER, M. L.. Simulação Baseada em System Dynamics para Avaliação de Cenários sobre Geração e Disposição de Resíduos Sólidos Urbanos. Production, São Paulo, v.24, n.1, p.212-224, 2014. DOI: http://dx.doi.org/10.1590/S0103-65132013005000034

SOUZA, W. S.. A Terceirização na Gestão Pública Federal das Instituições Escolares: um estudo de caso no setor de transportes do Instituto Federal de Educação, Ciência e Tecnologia do Triângulo Mineiro - Campus Uberlândia. Dissertação (Mestrado em Estudos Profissionais Especializados em Educação) - Instituto Politécnico do Porto, Porto, 2017.

VENTURINI, J. C.; PEREIRA, B. A. D.; MORALES, R.; FLECK, C. F.; JUNIOR, Z. B.; NAGEL, M. B.. Percepção da avaliação: um retrato da gestão pública em uma instituição de ensino superior (IES). Revista de Administração Pública, Rio de Janeiro, v.44, n.1, p.31-53, 2010. DOI: http://dx.doi.org/10.1590/S0034-76122010000100003

WILLIAMSON, O. E.. Markets and hierarchies: analysis and antitrust implications. New York: Free Press, 1975.

WILLIAMSON, O. E.. The mechanisms of governance. New York: Oxford University Press, 1996.

A CBPC - Companhia Brasileira de Produção Científica (CNPJ: 11.221.422/0001-03) detém os direitos materiais desta publicação. Os direitos referem-se à publicação do trabalho em qualquer parte do mundo, incluindo os direitos às renovações, expansões e disseminações da contribuição, bem como outros direitos subsidiários. Todos os trabalhos publicados eletronicamente poderão posteriormente ser publicados em coletâneas impressas sob coordenação da Sustenere Publishing, da Companhia Brasileira de Produção Científica e seus parceiros autorizados. Os (as) autores (as) preservam os direitos autorais, mas não têm permissão para a publicação da contribuição em outro meio, impresso ou digital, em português ou em tradução. 